\title{
Performance of Combined Water Turbine with Semielliptic Section of the Savonius Rotor
}

\author{
Kaprawi Sahim, Dyos Santoso, and Agus Radentan \\ Mechanical Engineering, Sriwijaya University, Jalan Raya Palembang-Prabumulih Km 32, Inderalaya 58062, Indonesia \\ Correspondence should be addressed to Kaprawi Sahim; kaprawi@unsri.ac.id
}

Received 12 March 2013; Accepted 8 May 2013

Academic Editor: Tariq Iqbal

Copyright (C) 2013 Kaprawi Sahim et al. This is an open access article distributed under the Creative Commons Attribution License, which permits unrestricted use, distribution, and reproduction in any medium, provided the original work is properly cited.

The Darrieus turbine is a suitable power generation in free stream flow because it is simple in construction, but it has the disadvantage of its small starting torque. The Savonius turbine has a high starting torque but the efficiency is smaller than that of Darrieus turbine. To improve the starting torque of Darrieus turbine, the Savonius buckets are introduced into the Darrieus turbine and the combined turbine is called Darrieus-Savonius turbine. In this study, three semielliptic sections of aspect ratio 0.8 were used for Savonius bucket while the Darrieus blade used three wings of airfoil NACA 0015. The Darrieus-Savonius turbine's performances were studied experimentally in an irrigation canal of South Sumatera, Indonesia. The results show that the distance of Savonius buckets from the shaft centre influences performance of combined turbine, and the attachment angle of Savonius rotor made important variation of turbine performance.

\section{Introduction}

Free stream flow of a river can be used to generate electricity by installing a suitable water turbine. Wide sources of stream flow like tides, marine current, irrigation canal, and industrial flows can make a source of electricity generation by installing water turbine rotor. Turbines for free stream flow are mainly aimed for rural region at sites remote from existing electricity grids, and they are useful machines to improve quality of life of people and increase the economic activities. In its installations, the turbine's rotors are fixed to a structure on the riverside or on floating pontoons.

Different designs of water turbine are available for the extraction of kinetic energy of free stream flow. Gorlov, Darrieus, and Savonius turbines are suitable for this purpose. The commonly uses of these turbines are vertical axis types. The Gorlov turbine has helically shaped blades which are of more complicated nature of the blade's construction. This could make Gorlov turbines at a serious disadvantage while the Darrieus turbine has straight bladed types, which are easy to be constructed. The Savonius turbine uses commonly a semicircular section which can be constructed by a semicircular pipe.
The efficiency of a helical turbine for free flow condition as reported analytically by Gorban et al. is about 35\% [1]. For Savonius turbine, most of the previous researchers used two buckets of semicircular section in exploring the performance. Kyozuka [2] gave an increase of value of coefficient of power of Savonius turbine by combination of Darrieus turbine having two wings and two Savonius buckets. Besides that the attachment angle $90^{\circ}$ gave a better coefficient of power when the turbine runs at low speed or better starting torque. Modified Savonius turbine without rotor shaft increases the coefficient of power as studied experimentally by Kamoji et al. [3].

Performance of Savonius rotor having more than two buckets was used to know the maximum rotation obtained when the turbine is used for exploring energy from ocean waves. This work was conducted by Hindasageri et al. [4], and it was reported that, in this case, the turbine having five buckets had the highest rotation. Three buckets of Savonius turbine were calculated by Sharma [5] in terms of static pressure and velocity of flow in buckets.

Deflector plates were used to improve the coefficient of power of Savonius turbine and the effect of interaction 
of Savonius turbine with side by side, triangular, and inline arrangement was also studied to obtain maximum coefficients of power $[6,7]$. The Darrieus turbine has some disadvantages. One of them is that it is not self-starting at the low speed. To overcome it, the variable-pitch turbine was constructed but the shaking force is still important [8].

The development of placement of Savonius rotor was investigated by Nakajima et al. [9]. The distance between the turbine rotor and the bottom wall of flow is an important parameter that influences the performance. Shiono et al. [10] gave experimentally the performances of Darrieus turbine in which the performance varies with solidity, velocity of flow, and blade inclination angle. The Savonius rotor with doublestep buckets was designed completely to produce electricity [11]. This double-step rotor was combined with the Darrieus turbine, called hybrid turbine, and this combined rotor gives experimentally the efficiency of $15 \%$ [12].

From the literature survey, all of Savonius buckets were in form of semicircular section. The present paper introduces a semielliptic bucket of Savonius rotor to improve self-starting of Darrieus rotor. The choice of this type of bucket is due to lower drag when compared with a semicircular form [13]. The elliptic buckets were installed to the Darrieus shaft with certain arm length. The aerodynamic performance of combined turbine was experimentally investigated on the basis of torque and power coefficients.

\section{Experimental Setup and Procedure}

Figure 1 gives the schematics of modified Darrieus-Savonius turbine in which three semielliptic buckets are used for Savonius and three wings for Darrieus turbine. The choice of this configuration is based on the smaller drag of an elliptic bucket than that of the circular one and three buckets are easy to start passively without other means. Besides that, by making an arm of Savonius buckets with length $h$ the rotor can produce higher effective torque but this makes higher torque due to drag force; actually the drag torque and the effective torque are in opposite direction. The dimensionless distance from the rotor shaft centre is denoted by $L=h / r$, where $r$ is radius of Darrieus rotor and $h$ is the distance of Savonius buckets from shaft centre.

In this study, it is aimed to know the effect of bucket's distance from the rotor shaft centre and the attachment angles on the torque and the power of combined turbine. In this case, two configurations of Savonius buckets are set at distances $L$ $=0.36$ and 0.79 . The attachment angle is chosen for two cases; that is, $\beta=0^{\circ}$ and $\beta=60^{\circ}$.

The symmetrical blade of NACA 0015 is used for Darrieus rotor. This choice was based on the smaller drag either due to friction or pressure. The span length of the blade was $300 \mathrm{~mm}$, and the chord length was $63 \mathrm{~mm}$. The solidity of Darrieus rotor is kept constant at 0.20 in this study and is calculated by

$$
\sigma=\frac{c B}{\pi d}
$$

where $c, B$, and $d$ are the chord length, the number of wings and the turbine diameter, respectively. The wings were made

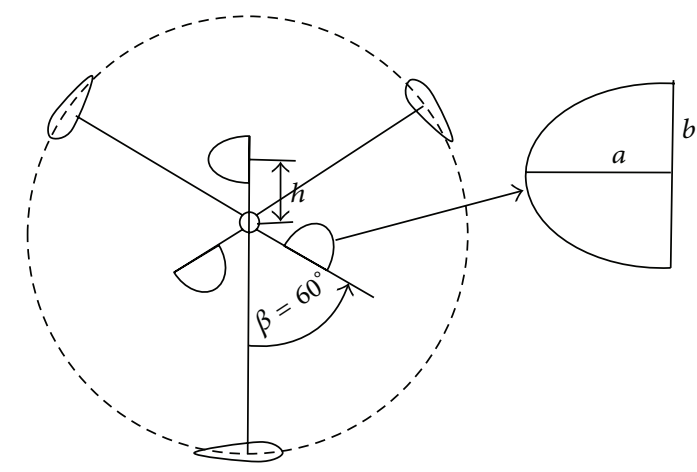

Figure 1: Combined Darrieus-Savonius turbine.

up of wood, and the surface was coated with smooth layers of plastics, while semielliptic section was made up of polyvinyl chloride (PVC) material for Savonius buckets and with length of semimajor axis $a=66 \mathrm{~mm}$ and semiminor axis $b=53 \mathrm{~mm}$, so the aspect ratio was 0.8 . The span length of Savonius was the same as the span length of Darrieus wing.

The schematic view of turbine's installation and torque meter is shown by Figure 2. The combined turbine was mounted to frame (6) by using sealed bearing (3) and is equipped with brake wheel dynamometer (7). The wings and buckets (1) were attached to the arm (8) by bolts, which facilitate the easy replacement. A rope brake dynamometer is used for loading the Darrieus-Savonius turbine. The turbine was submerged in free stream flow, and the water level was held beyond the upper bearing. The weighing pan (4) and spring balance (2) were connected by means of a rope. The rotor is loaded gradually from idle condition to record spring balance reading, weight, and rotational speed of the rotor. The load was added by a mass on weighing pan until the rotor stopped to rotate or in which the maximum load reached. For each load, rotation speed was measured by means of a tachometer, and then it is converted into the dimensionless form, called tip speed ratio expressed as follows:

$$
\lambda=\frac{U}{U_{o}}
$$

where $U_{o}$ and $U$ are the velocity of free stream velocity and tangential velocity of Darrieus rotor, respectively. The flow velocity was measured by a digital current meter.

The effective braking torque is calculated from the measured load and spring balance load. The coefficients of torque and power are as follows:

$$
\begin{gathered}
T=9.81(W-S) \cdot\left(\frac{D_{b}+D_{r}}{2}\right), \\
C_{p}=C_{t} \cdot \lambda .
\end{gathered}
$$

The turbine was not loaded by any other electrical means (e.g., generator) because the mechanical energy resulting from the test may be converted to electrical energy. We limit the test to measure the mechanical energy output from the turbine. If a generator is installed, the electrical energy output depends upon the efficiency of generator. 


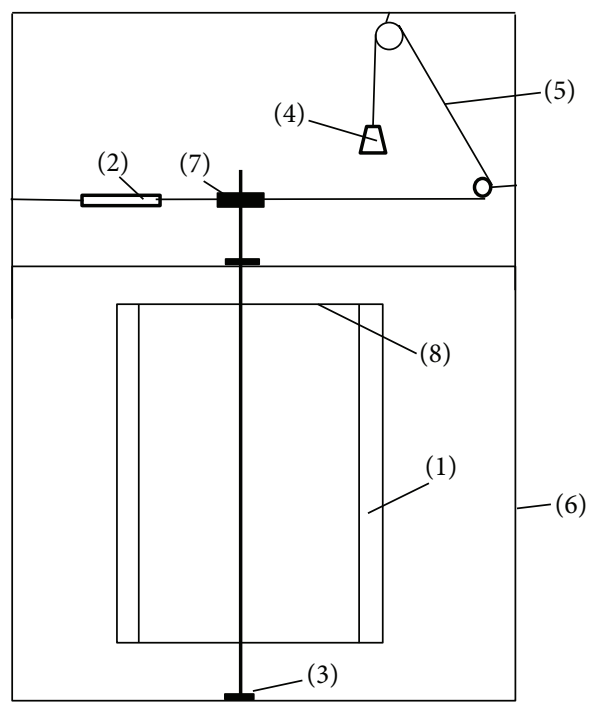

(a)

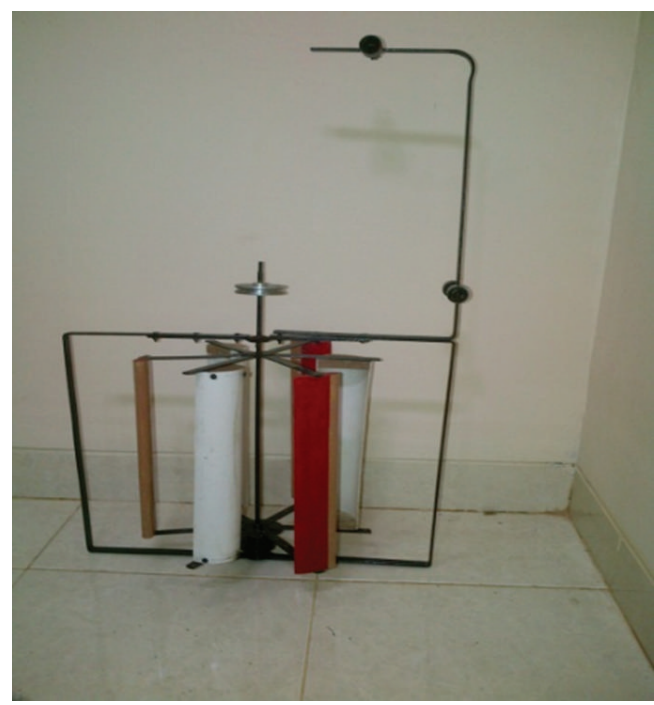

(b)

Figure 2: (a) Schematic diagram of the test setup, (b) experimental setup.

The test was conducted in water flow of constant velocity $0.61 \mathrm{~m} / \mathrm{s}$ in an irrigation canal of $1 \mathrm{~m}$ wide and $0.60 \mathrm{~m}$ water depth (Figure 3(b)) located in Gumawang Village, Indonesia. The flow in the canal comes from the upstream canal of $2 \mathrm{~m}$ wide by a converging canal as shown by Figure 3(a). Water velocity in canal was kept constant because of the flow system in mounted river dam by a sluice gate. This system makes the water overflows over the dam when the debit increases in the main canal (river).

\section{Results and Discussion}

Experiments are conducted to determine the coefficients of torque and power for the different positions of semielliptic Savonius buckets in combined Darrieus-Savonius machine.

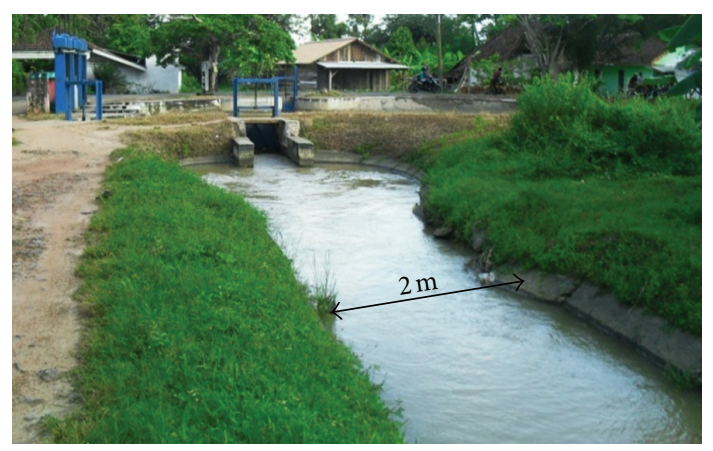

(a)

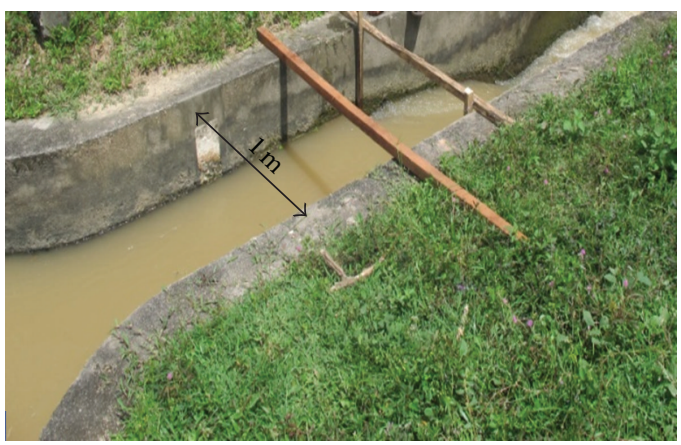

(b)

FIgURE 3: Irrigation canal for turbine test.

Three positions were studied. Savonius buckets are placed at the same arm as that of Darrieus at near distance from the rotor shaft centre and buckets are placed $60^{\circ}$ from the Darrieus having two different distances from the shaft. The other tests are conducted for solo Darrieus, without Savonius buckets, and solo Savonius, without Darrieus wing. Figure 4 shows that the coefficient of torque varies with the tip speed ratio, $\lambda$. All curves increase with decrease of tip speed ratio because of load addition.

The turbine was tested starting from no-load condition, which makes maximum rotation. When the load increased, the speed of rotor decreased and at certain load, turbine rotor stopped rotating because the turbine was overloaded, which could not generate torque. This is the reason that there are no data points on the left half of the curve. Maximum coefficient of torque of solo Savonius is higher than that of solo Darrieus, that is, 0.087 for Darrieus at $\lambda=1.6$ and 0.0946 for Savonius at $\lambda=0.6$. In this condition, the axes of Savonius buckets were located at dimensionless distance $L=$ 0.79 from the rotor shaft centre, and the Darrieus wings were located at $L=1$. At idle condition or zero torque, the speed of Darrieus rotor is about twice higher than that of Savonius. The torque variations of Darrieus rotor occurred at speed of wide range while for Savonius it occurred at speed of small ranges. Clearly Savonius rotor experiences higher drag.

If Darrieus and Savonius turbines are combined into one unit in which Savonius buckets are inserted within Darrieus rotor, the maximum torque becomes higher at low speed except for Darrieus-Savonius turbine with $L=0.36$ and $\beta=0^{\circ}$. The significant highest torques occurring for turbine 


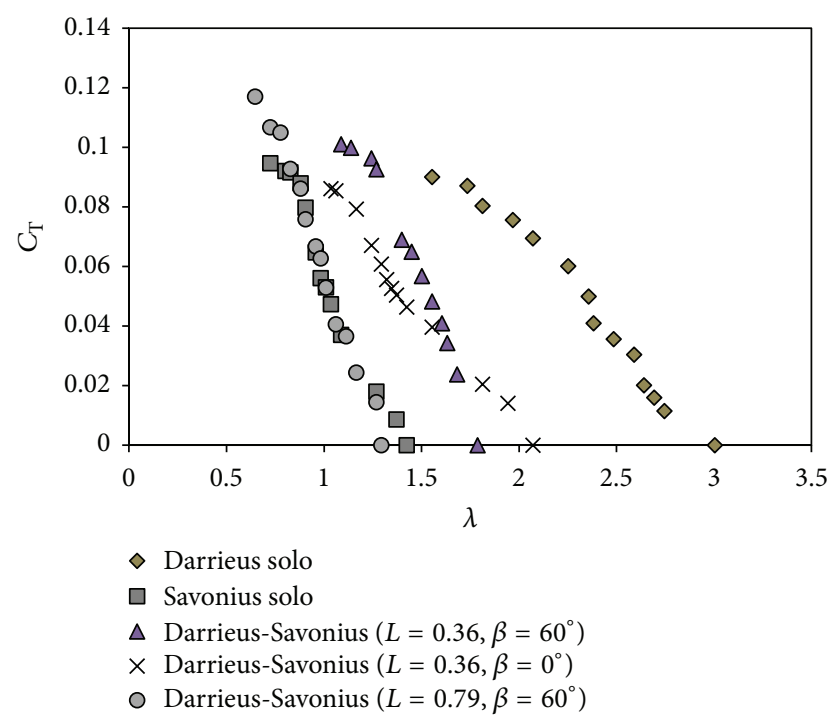

Figure 4: Coefficient of Torque.

where $L=0.79$ and $\beta=60^{\circ}$ reach 0.12 at $\lambda=0.6$, but on the other hand, the speed range is practically the same as that of solo Savonius rotor. For combined turbine where $L$ $=0.36$ and $\beta=60^{\circ}$, we observe that the torque lies within the speed range between solo Darrieus and Savonius and the maximum torque occurs at $\lambda=1.2$. The torque higher than both solo Darrieus and Savonius reaches 0.10. The torque variation shows the interaction of the Darrieus and Savonius torques' variations.

Power is obtained by the multiplication of torque and angular speed of rotor, and then it is transformed into the dimensionless form called the coefficient of power which the measured torque compared to the ideal torque. The coefficients of power variations are shown by Figure 5. It is observed that the speed limit for solo Darrieus ranges from $\lambda$ $=1.6$ to 3 and for solo Savonius from $\lambda=0.7$ to 1.4. The first has the highest value which attains 0.15 at about $\lambda=1.75$ while the latter has maximum coefficient of power $C_{p}=0.08$ at $\lambda=$ 0.8 . The difference is about $45 \%$ and it is a significant case.

In the combined turbine, the coefficient of power variation lies between the two values where the maximum and minimum values are between the values of solo Darrieus and Savonius, respectively. It is observed that combined turbine has the lowest values of a coefficient of power if $L=0.79$ and $\beta=60^{\circ}$ and the turbine has practically the same variation of torque as that of solo Savonius for certain limit of tip speed ratio (Figure 4).

For combined machine with $L=0.36$ and $\beta=60^{\circ}$, the maximum coefficient of power is higher than that of solo Savonius and it has a maximum value of 0.12 . When it is compared to the Darrieus, the difference of the coefficients of power is about $20 \%$ smaller, but the torque improves by $11 \%$ as shown in Figure 4. The limit of operation speed of the turbine is in the range of $1.2<\lambda<2.1$.

For the three different combined machines, there is no convenient value of $C_{p}$, which is higher than that of Darrieus machine. Therefore, it is necessary to seek potential

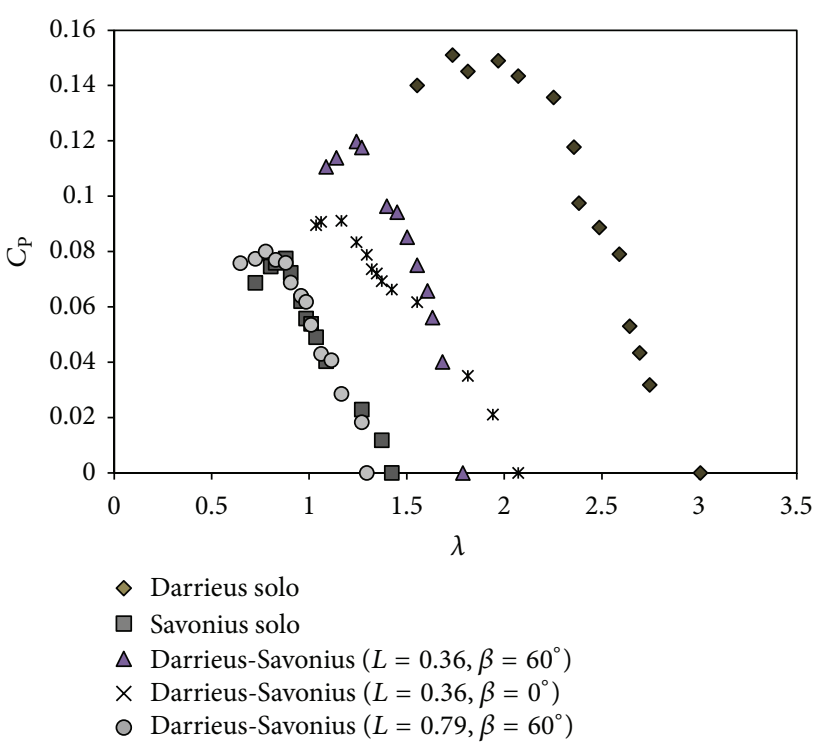

Figure 5: Coeffient of Power.

compromises between coefficients of torque and power. The combined machine with $L=0.36$ and $\beta=60^{\circ}$ seems to be a convenient choice, though its efficiency is lower than that of solo Darrieus, but in a river application, this can be overcome by installing many turbines to fulfil the needed power.

\section{Conclusions}

Among the combined turbines that have been studied experimentally, two configurations of combined turbines for $L=$ $0.79, \beta=60^{\circ}$ and $L=0.36, \beta=60^{\circ}$ improve the torque at low speeds. One of these combined turbines, turbine with $L=0.36$ and $\beta=60^{\circ}$, has higher coefficient of power. The Savonius buckets give better performance if they are located near the shaft centre, and the position is located at the middle of Darrieus wing or not at the same arm as that of Darrieus wing. The presence of Savonius rotor makes Darrieus turbine become easily self-starting at low speed. This study gives the limitations of uses of Darrieus-Savonius turbine, which may be important as the base of a design in its application.
Abbreviations
a: Semimajor axis of elliptic section (mm)
$b$ : Semiminor axis of elliptic section $(\mathrm{mm})$
$B$ : Number of wings
$c$ : Chord length of wing $(\mathrm{mm})$
$C_{p}$ : Coefficient of power
$C_{T}$ : Coefficient of torque
$D_{h}$ : Diameter of drum brake dynamometer $(\mathrm{mm})$
$D_{r}$ : Diameter of rope $(\mathrm{mm})$ 
$h$ : Distance from bucket to shaft ( $\mathrm{mm}$ )

L: Dimensionless distance from bucket to shaft $(h / r)$

$r$ : Radius of Darrieus rotor $(\mathrm{mm})$

$S: \quad$ Spring balance load (gr)

T: Torque (Nm)

$U$ : Tangential velocity of Darrieus rotor $(\mathrm{m} / \mathrm{s})$

$U_{o}$ : Free stream velocity $(\mathrm{m} / \mathrm{s})$

$W$ : Dead load on brake (kgf).

\section{Greek Symbols}

$\beta$ : Attachment angle $\left({ }^{\circ}\right)$

$\lambda$ : Tip speed ratio $\left(U / U_{o}\right)$

$\varepsilon$ : Aspect ratio $\left(U / U_{o}\right)$

$\sigma$ : Turbine solidity.

\section{References}

[1] A. N. Gorban', A. M. Gorlov, and V. M. Silantyev, "Limits of the turbine efficiency for free fluid flow," Journal of Energy Resources Technology, Transactions of the ASME, vol. 123, no. 2-4, pp. 311317, 2001.

[2] Y. Kyozuka, "An experimental study on the Darrieus-Savonius turbine for the tidal current power generation," Journal of Fluid Science and Technology, vol. 3, no. 3, pp. 439-449, 2008.

[3] M. A. Kamoji, S. B. Kedare, and S. V. Prabhu, "Experimental investigations on single stage modified Savonius rotor," Applied Energy, vol. 86, no. 7-8, pp. 1064-1073, 2009.

[4] V. . Hindasageri, H. Ramesh, and S. C. Kattimani, "Performance of Savonius Rotors for utilizing the orbital motion of Ocean Waves in Shallow waters," Journal of Sustainable Energy \& Environment, vol. 2, pp. 117-119, 2001.

[5] G. R. K. . Sharma, "Flow Physics of a Three-Bucket Savonius Rotor using Computational Fluid Dynamics (CFD)," International Journal of Research in Mechanical Engineering and Technology, vol. 1, no. 1, pp. 46-51, 2011.

[6] K. Golecha, T. I. Eldho, and S. V. Prabhu, "Study on the interaction between two hydrokinetic Savonius turbines," International Journal of Rotating Machinery, vol. 2012, Article ID 581658, 10 pages, 2012.

[7] K. . Golecha, T. I. Eldho, and S. V. Prabhu, "Investigation on the performance of a modified Savonius water turbine with single and two deflector plates," in Proceedings of the 11th Asian International Conference on Fluid Machinery and The 3rd Fluid Power Technology Exhibition, pp. 1-13, IIT Madras, November 2011.

[8] B. . Kirke and L. Lazauskas, "Variable Pitch Darrieus water turbines," Journal of Fluid Science and Technology, vol. 3, no. 3, pp. 430-438, 2008.

[9] M. Nakajima, S. Lio, and T. Ikeda, "Performance of double-step Savonius rotor for environmentally friendly hydraulic turbine," Journal of Fluid Science and Tehnology, vol. 3, no. 3, pp. 410-419, 2008.

[10] M. Shiono, K. Suzuki, and S. Kiho, "Output characteristics of Darrieus water turbine with helical blades for tidal current generations," in Proceedings of the 12th International Offshore and Polar Engineering Conference, pp. 859-864, Kitakyushu, Japan, May 2002.
[11] J. L. Menet, "A double-step Savonius rotor for local production of electricity: a design study," Renewable Energy, vol. 29, no. 11, pp. 1843-1862, 2004.

[12] M. J. Alam and M. T. Iqbal, "A low cut-in speed marine current turbine," Journal of Ocean Technology, vol. 5, no. 4, pp. 49-62, 2010.

[13] Y. A. Cangel, J. M. Cimbala, and R. H. Turner, Fundamentals of Thermal Fluid Science, McGraw-Hill, 4th edition, 2008. 

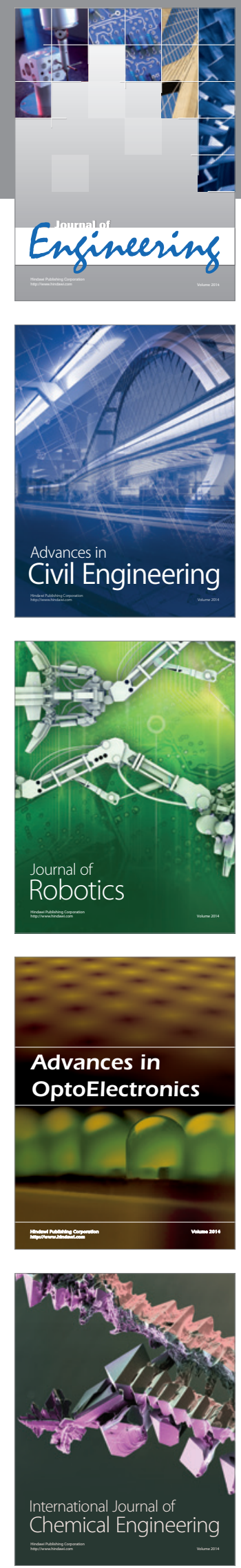

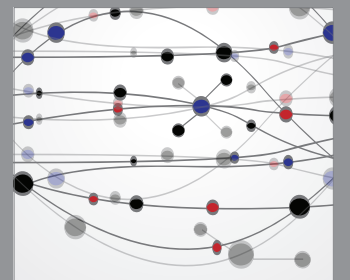

The Scientific World Journal
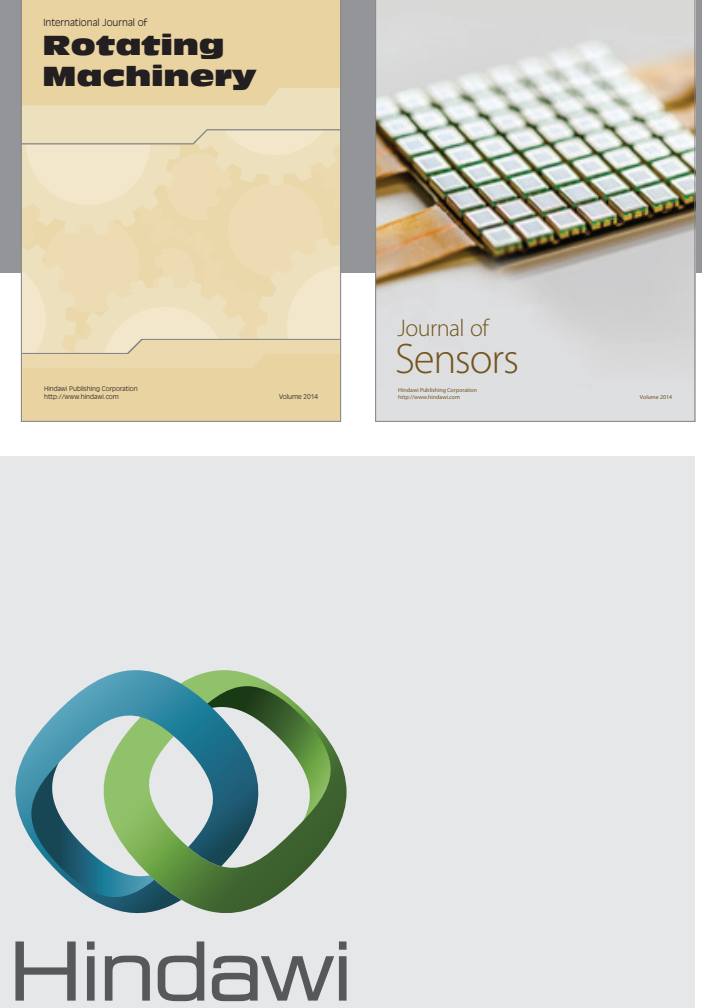

Submit your manuscripts at http://www.hindawi.com
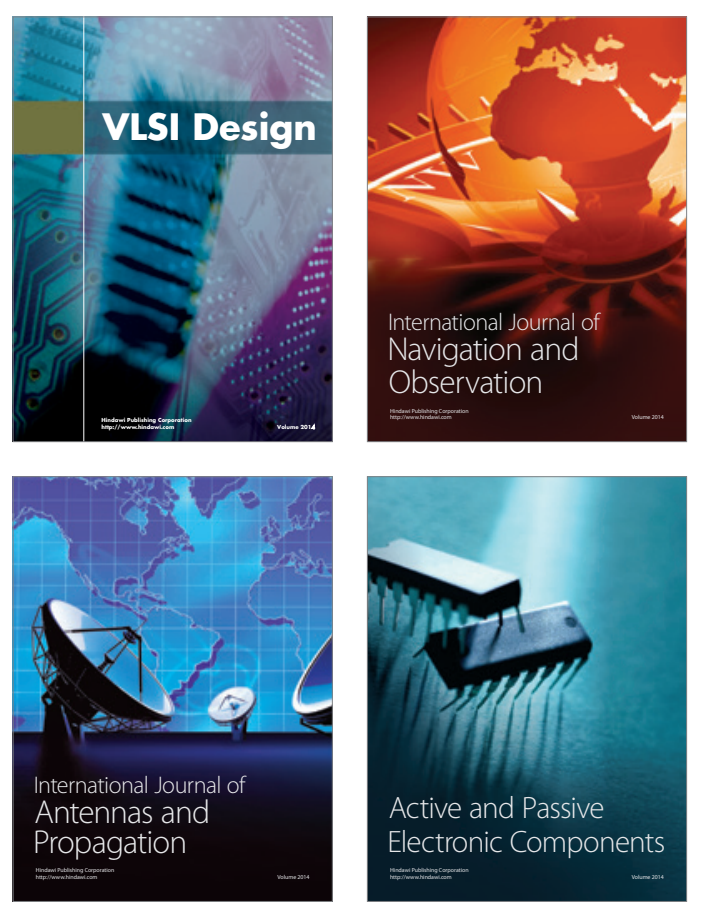
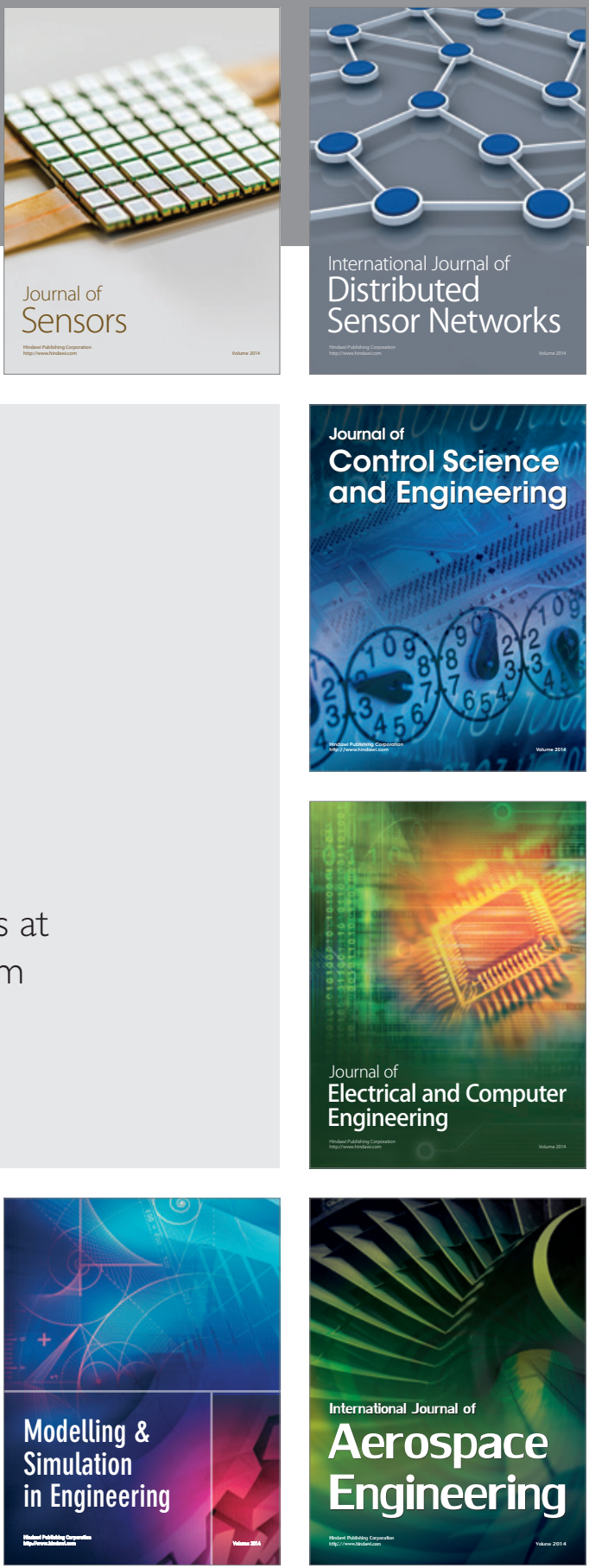

Journal of

Control Science

and Engineering
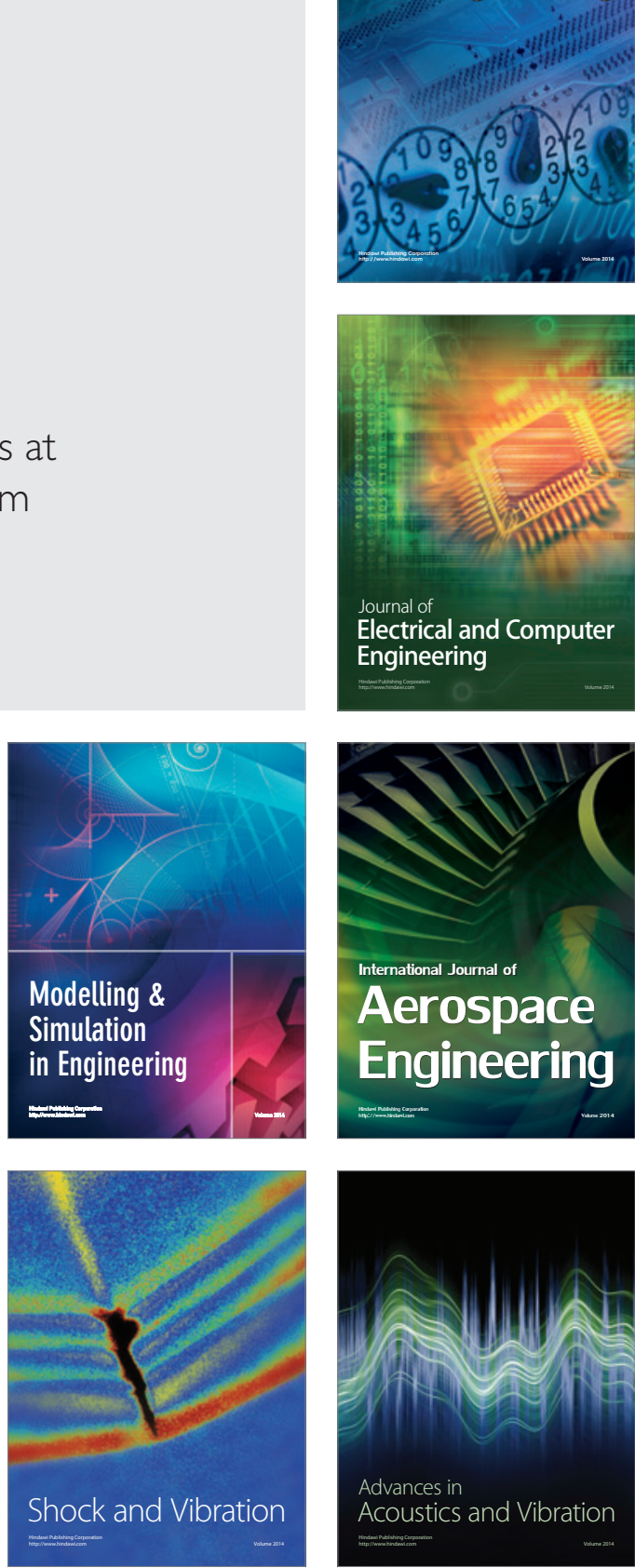